CLINICAL STUDY

\title{
Transcriptional profiling enables molecular classification of adrenocortical tumours
}

\author{
Cecilia Laurell*, David Velázquez-Fernández ${ }^{1, *}$, Kristina Lindsten ${ }^{2}$, Christofer Juhlin ${ }^{1}$, Ulla Enberg ${ }^{1}$, Janos Geli ${ }^{1}$, \\ Anders Höög ${ }^{3}$, Magnus Kjellman ${ }^{1}$, Joakim Lundeberg, Bertil Hamberger ${ }^{1}$, Catharina Larsson ${ }^{1}$, Peter Nilsson \\ and Martin Bäckdahl ${ }^{1}$ \\ School of Biotechnology, KTH-Royal Institute of Technology, 11427 Stockholm, Sweden, Departments of ${ }^{1}$ Molecular Medicine and Surgery, ${ }^{2}$ Cell and \\ Molecular Biology and ${ }^{3}$ Oncology-Pathology, Karolinska Institutet, 17176 Stockholm, Sweden \\ (Correspondence should be addressed to C Laurell; Email: claurell@kth.se)
}

*(C Laurell and D Velázquez-Fernández contributed equally to this work)

\begin{abstract}
Objective: Tumours in the adrenocortex are common human tumours. Malignancy is however, rare, the yearly incidence being 0.5-2 per million inhabitants, but associated with a very aggressive behaviour. Adrenocortical tumours are often associated with altered hormone production with a variety of clinical symptoms. The aggressiveness of carcinomas together with the high frequency of adenomas calls for a deeper understanding of the underlying biological mechanisms and an improvement of the diagnostic possibilities.

Methods: Microarray gene expression analysis was performed in tumours of adrenocortex with emphasis on malignancy as well as hormonal activity. The sample set consisted of 17 adenomas, 11 carcinomas and 4 histological normal adrenocortexes. RNA from these was hybridised according to a reference design on microarrays harbouring 29760 human cDNA clones. Confirmation was performed with quantitative real time-PCR and western blot analysis.

Results: Unsupervised clustering to reveal relationships between samples based on the entire gene expression profile resulted in two subclusters; carcinomas and non-cancer specimens. A large number of genes were accordingly found to be differentially expressed comparing carcinomas to adenomas. Among these were IGF2, FGFR1 and FGFR4 in growth factor signalling the most predominant and also the USP4, UBE2C and UFD1L in the ubiquitin-proteasome pathway. Moreover, two subgroups of carcinomas were identified with different survival outcome, suggesting that survival prediction can be made on the basis of gene expression profiles. Regarding adenomas with aldosterone overproduction, $O S B P$ and VEGFB were among the most up-regulated genes compared with the other samples.

Conclusions: Adrenocortical carcinomas are associated with a distinct molecular signature apparent in their gene expression profiles. Differentially expressed genes were identified associated with malignancy, survival as well as hormonal activity providing a resource of candidate genes for an exploration of possible drug targets and diagnostic and prognostic markers.
\end{abstract}

European Journal of Endocrinology 161 141-152

\section{Introduction}

Adrenocortical tumours have a relatively high prevalence in the general population of up to $9 \%$ in autopsy studies $(1,2)$. However, malignancy is rare, the yearly incidence being 0.5-2 per million people, but with only 12 months mean survival time for patients with nonresectable cancers (3-7). The aggressiveness of carcinomas together with the high frequency of adenomas calls for a deeper understanding of the underlying biological mechanisms and an improvement of the diagnostic possibilities.

Most adrenocortical tumours are detected incidentally with computed tomography (CT) or magnetic resonance imaging (MRI), although some give clinical signs, associated with the specific hormone over-expressed, e.g. aldosterone or cortisol. Adenoma development sometimes leads to overproduction of one or a mixture of these hormones. Aldosterone producing tumours (aldosteronomas) causes hypertension, while cortisol overproduction induces Cushing's syndrome. Adrenocortical carcinomas are often large and may therefore be present with abdominal pain and weight loss, with or without a mixture of the different hormones. The hormonal profiles associated with adrenocortical tumours makes hormonal screening an appealing clinical approach for diagnosis and analyses of steroid profiles may also contribute to set the malignant diagnosis. As a result of the recent advances in the bioimaging field and the more frequent use of CT and 
MRI, the number of detected tumours is increasing. The main indication for adrenalectomy of tumours without hormone overproduction is the size of the tumour based on CT and MRI. All tumours with a diameter larger than $4 \mathrm{~cm}$ are, in most countries, recommended to be surgically resected (8). Development of adrenocortical carcinoma is not well characterised. Comparative hybridisation studies and allelotyping have shown that the number of genetic alterations increases with tumour size as a sign of an overall altered genetic stability in the malignant tumours $(4,5,9)$. The most common genetic aberrations are gains on chromosome 4 and 5 and losses on chromosome 11 and 17. Also in benign tumours gains have been observed, on the long arm of chromosome 4 (10). Mutations of TP53 as well as over-expression of IGF 2 due to $\mathrm{CpG}$ island demethylation are shared features of malignant tumours (11).

Tumour classification based on microarray gene expression data has demonstrated promising results for numerous cancer types with potential clinical applications (12-15). There are principally two categories of classification: unsupervised and supervised, which are used for two different purposes. Unsupervised classification is mainly used for exploratory analysis, clustering tumours into groups based on similarities of gene expression profiles. If the resulting clusters have concordance with diagnosis or outcome the unsupervised clustering method can be used as a diagnostic and prognostic tool. Supervised classification on the other hand is always performed to create a diagnostic tool, which is to be used for discrimination of new data. Development of the classifier is based on prior information of how tumour types are connected to the appearance of gene expression profiles. This can be obtained by performing microarray analysis on samples with well-established diagnosis and with long follow-up.

In a previous microarray study (16), we have shown that adrenocortical carcinomas have gene expression signatures that can be distinguished from adenomas. In this report the sample size has been increased and we further analyse transcriptional differences in subtypes of hormone producing adrenocortical tumours, incidentalomas and normal adrenal cortex. Furthermore, based on the gene expression profiles, we suggest candidates for potential markers for the diagnosis of adrenocortical carcinoma. We also show that the carcinoma tumours cluster into two separate groups correlated to the survival time.

\section{Methods}

\section{Tissue samples}

This study included 4 normal adrenal cortex samples and all together 28 sporadic adrenocortical tumours; 4 aldosteronomas, 5 cortisol producing adenomas (here denoted as Cushing in figures and tables),
8 incidentalomas and 11 adrenocortical carcinomas. Cases with incidentaloma did not exhibit hormonal overproduction as determined by urinary and serum measurements. A subset of the tumours, 7 carcinomas and 13 adenomas, were included in a previous study and the data has been integrated into this extended study (16). All cases were selected from a cohort of 250 patients operated at the Karolinska University Hospital from 1986 to 2004 as described (16). Excluded cases were those with adrenal hyperplasia or tumours from the adrenal medulla. The tumour tissue analysed contained more than $70 \%$ tumour cells. Every patient had a clinical follow-up for at least 1.5 years. Diagnostic criteria for malignancy were vascular invasion, invasion of surrounding organs and/or presence of distant metastasis. In cases where these criteria were not fulfilled the histopathological criteria proposed by Weiss was used (17). Cases with high nuclear grade, increased mitotic figures and tumour necrosis were suspected to be malignant. The appearance of metastasis at follow-up, or recurrences further facilitated the establishment of a malignant diagnosis. Normal adrenal cortex samples were obtained from patients undergoing nephrectomy for other reasons and used as normal references in the RNA analysis. Matching normal adrenal cortex was obtained from four of the cases for western blot analysis. The clinical and tumour characteristics are shown in Table 1. The samples were obtained with informed consent and the study of the tissue material was approved by the Ethical Committee of the Karolinska University Hospital.

\section{RNA extraction}

A fresh frozen piece of $\sim 100 \mathrm{mg}$ was used for RNA extraction. Representative sections from all specimens were subjected to histopathological evaluation for tumour representativity. Total RNA was extracted using Qiagen mini and midi preps kits for RNA purification. RNA quantity and quality were assessed by an ND-1000 spectrophotometer (Nanodrop, San Francisco, CA, USA) and 2100 Bioanalyzer (Agilent Technologies, Santa Clara, CA, USA).

\section{Design of microarray experiments}

We used a reference design where each sample was hybridised in duplicates. Tumour samples were labelled with $\mathrm{Cy} 5$ and hybridised with $\mathrm{Cy} 3$ labelled commercially available Universal Human Reference RNA (UHRR; Stratagene, La Jolla, CA, USA).

\section{Microarray production}

In-house manufactured cDNA microarrays with 29760 cDNA fragments representing 18953 unique human UniGene IDs were used. The cDNA clones originate from the sequence verified human clone 
Table 1 Clinical data of analysed cases.

\begin{tabular}{|c|c|c|c|c|c|c|c|c|}
\hline Case no. & $\begin{array}{l}\text { Histopathological } \\
\text { diagnosis }\end{array}$ & Subtype & Age & Sex & Metastasis & $\begin{array}{l}\text { Survival } \\
\text { (months) }^{\mathrm{a}}\end{array}$ & $\begin{array}{l}\text { Weight } \\
\text { (g) }\end{array}$ & $\begin{array}{l}\text { Size } \\
(\mathrm{cm})\end{array}$ \\
\hline 50 & Cancer & Cancer & 63 & $\mathrm{~F}$ & Liver and bone & $6^{\mathrm{DoD}}$ & 1500 & 20 \\
\hline 372 & Cancer & Cancer & 78 & $M$ & No & $3^{\mathrm{DoD}}$ & 203 & 15 \\
\hline 882 & Cancer & Cancer & 72 & $\mathrm{~F}$ & No & $5^{\mathrm{DoD}}$ & 85 & 7 \\
\hline 1559 & Cancer & Cancer & 72 & $M$ & Lung & 120 & 1036 & 11 \\
\hline 1739 & Cancer & Cancer & 40 & $\mathrm{~F}$ & No & 120 & 2350 & 13 \\
\hline 1780 & Cancer & Cancer & 56 & $\mathrm{~F}$ & Liver and lungs & $9^{\mathrm{DoD}}$ & 309 & 9 \\
\hline 2582 & Cancer & Cancer & 54 & $\mathrm{~F}$ & Liver & $4^{\mathrm{DoD}}$ & 1339 & 15 \\
\hline 2716 & Cancer & Cancer & 68 & $\mathrm{M}$ & No & 69 & 1420 & 15 \\
\hline 2931 & Cancer & Cancer & 52 & $M$ & No & 67 & 660 & 11 \\
\hline 3072 & Cancer & Cancer & 68 & $\mathrm{M}$ & Liver & 53 & 660 & 12 \\
\hline 3410 & Cancer & Cancer & 84 & $\mathrm{~F}$ & Liver & $32^{\mathrm{DoD}}$ & 1700 & 19 \\
\hline 885 & Adenoma & Cushing & 38 & $\mathrm{~F}$ & - & 151 & 12 & 3 \\
\hline 1206 & Adenoma & Cushing & 63 & $\mathrm{~F}$ & - & 146 & 51 & 6 \\
\hline 3374 & Adenoma & Cushing & 66 & $\mathrm{~F}$ & - & 50 & 14 & 2 \\
\hline 4232 & Adenoma & Cushing & 35 & $\mathrm{~F}$ & - & 20 & 26 & 4 \\
\hline 4539 & Adenoma & Cushing & 42 & $\mathrm{~F}$ & - & 18 & 28 & 4 \\
\hline 501 & Adenoma & Aldosteronoma & 50 & $\mathrm{~F}$ & - & 181 & NA & 2 \\
\hline 1077 & Adenoma & Aldosteronoma & 47 & $\mathrm{M}$ & - & 144 & NA & 3 \\
\hline 1105 & Adenoma & Aldosteronoma & 29 & $\mathrm{~F}$ & - & 143 & 9 & 2 \\
\hline 1196 & Adenoma & Aldosteronoma & 79 & $\mathrm{~F}$ & - & $112^{\mathrm{b}}$ & 7 & 2 \\
\hline 1180 & Adenoma & Incidentaloma & 63 & $\mathrm{~F}$ & - & 140 & 36 & 5 \\
\hline 1191 & Adenoma & Incidentaloma & 63 & $\mathrm{M}$ & - & 140 & 32 & 4 \\
\hline 1764 & Adenoma & Incidentaloma & 42 & $\mathrm{~F}$ & - & 110 & 17 & 3 \\
\hline 2302 & Adenoma & Incidentaloma & 64 & $\mathrm{~F}$ & - & 86 & 26 & 4 \\
\hline 2414 & Adenoma & Incidentaloma & 63 & $\mathrm{~F}$ & - & 84 & 22 & 4 \\
\hline 2915 & Adenoma & Incidentaloma & 66 & $\mathrm{M}$ & - & 61 & 22 & 4 \\
\hline 3669 & Adenoma & Incidentaloma & 54 & $\mathrm{~F}$ & - & 31 & 29 & 4 \\
\hline 3793 & Adenoma & Incidentaloma & 59 & $\mathrm{~F}$ & - & 28 & 19 & 3 \\
\hline 3234 & Adrenal & Normal & 81 & $\mathrm{M}$ & - & - & - & - \\
\hline 4149 & Adrenal & Normal & 36 & $\mathrm{~F}$ & - & - & - & - \\
\hline 4166 & Adrenal & Normal & 85 & M & - & - & - & - \\
\hline 5179 & Adrenal & Normal & 76 & $\mathrm{M}$ & - & - & - & - \\
\hline
\end{tabular}

DoD, dead of disease.

${ }^{\text {a } T i m e ~ b e t w e e n ~ s u r g e r y ~ a n d ~ f o l l o w-u p . ~}$

${ }^{\mathrm{b}}$ Dead.

collection, 97001.V, plates 1-310 (Research Genetics Inc., Huntsville, AL, USA). The microarrays were spotted onto Ultra GAPS slides (Corning, Lowell, MA, USA) with a Qarray 2 arrayer with 48 K2805 pins (Genetix, Hampshire, UK). The complete protocols for preparation of clones and printing together with a complete gene list can be found at www.ktharray.se and at ArrayExpress (A-MEXP-114).

\section{Target labelling}

First strand cDNA target was generated by RT of $10 \mu \mathrm{g}$ of total RNA in a $30 \mu \mathrm{l}$ reaction using $5 \mu \mathrm{g}$ random hexamers (Operon), first-strand buffer (50 mM Tris$\left.\mathrm{HCl}, \mathrm{pH} 8.3,75 \mathrm{mM} \mathrm{KCl}, 3 \mathrm{mM} \mathrm{MgCl}_{2}\right), 0.01 \mathrm{mM}$ dithiothreitol (DTT), 400 units Superscript III (Invitrogen), $2 \mathrm{mM} \mathrm{d}(\mathrm{A} / \mathrm{G} / \mathrm{C}) \mathrm{TPs}, 1.6 \mathrm{mM}$ dTTP (Amersham Biosciences) and $0.4 \mathrm{mM}$ aminoallyl-dUTP (SigmaAldrich). Secondary structures of RNA and primers were removed at $70{ }^{\circ} \mathrm{C}$ during $10 \mathrm{~min}$ followed by $2 \mathrm{~min}$ of incubation on ice for primer annealing before addition of the other reaction components. cDNA synthesis was performed for $2 \mathrm{~h}$ at $42{ }^{\circ} \mathrm{C}$ and terminated by addition of EDTA. The RNA was hydrolysed in $\mathrm{NaOH}$ during $15 \mathrm{~min}$ incubation at $70{ }^{\circ} \mathrm{C}$ followed by neutralisation with $\mathrm{HCl}$ (final concentrations 20,150 and $150 \mathrm{mM}$, respectively). The cDNA was purified using MinElute spin columns (Qiagen) with the provided wash buffer replaced by $80 \%$ ethanol and the elution buffer by $100 \mathrm{mM} \mathrm{NaHCO}_{3}, \mathrm{pH}$ 9.0. Monofunctional NHS-ester $\mathrm{Cy} 3$ or $\mathrm{Cy} 5$ fluorophores (Amersham Biosciences) were coupled to the amino-allyl groups during a 30-min incubation at room temperature after which unincorporated ester groups were inactivated through a hydroxylamine treatment (final concentration of $730 \mathrm{mM}$ ). The labelling reactions were purified using MinElute spin columns. The complete protocol for target labelling can be downloaded from www.ktharray.se. Extraction and labelling quality/quantity were assessed with an ND-1000 spectrophotometer (Nanodrop).

\section{Hybridisations and scanning}

The slides were prehybridised in $5 \times$ SSC, $0.1 \%$ SDS and $1 \%$ BSA (Sigma-Aldrich) for $30 \mathrm{~min}$ in $42{ }^{\circ} \mathrm{C}$. The 
hybridisation buffer contained $50 \%$ formamide, $5 \times$ SSC, $0.1 \%$ SDS, $10 \mu \mathrm{g}$ COT-1 DNA (Invitrogen) and $5 \mu \mathrm{g}$ tRNA (Sigma-Aldrich). After hybridisations in chambers (Corning) for $18 \mathrm{~h}$ at $42^{\circ} \mathrm{C}$ the arrays were washed according to Corning's recommendations and scanned at 532 and $635 \mathrm{~nm}$ with $10-\mu \mathrm{m}$ resolution using a G2565BA DNA microarray scanner (Agilent Technologies).

\section{Data analysis}

Image analysis was performed in GenePix Pro 5.1 software (Axon Instruments Inc., Foster City, CA, USA). Spots were removed from further analysis if more than $70 \%$ of foreground pixels were below background intensity plus two S.D.s in both channels or if the difference between ratio of medians and regression ratio exceeded $20 \%$ in one of the channels. After removal of the low quality spots the remaining intensities were print tip lowess normalised in the $\mathrm{R}$ environment for statistical computing (18) with the aroma package (19). To increase robustness considering the limited amount of patients, probe signals were required to be present in at least one technical replicate for each patient to be considered in the further analysis (6063 probes representing 4843 unique UniGene IDs). An exception was made in the comparison of aldosteronomas to all other samples where a maximum of five missing values were allowed in non-aldosteronoma specimens (12059 probes representing 8880 unique UniGene IDs). An empirical Bayes statistics (B-test) for ranking differentially expressed genes according to statistical significance was performed with the Limma package (20). The criteria for statistical significance in the supplementary data files of differentially expressed genes were $P<0.001$ and $\log _{2}$ fold change $>1$. The $P$ value is the Benjamini and Hochberg false discovery rate. Fischer's exact test was used for enrichment analysis of Gene Ontology (GO) terms and chromosomal location among the 1000 most significantly differentially expressed genes comparing malignant to non-malignant samples with a significance level of $P<0.05$. Clustering was performed with the stats and class packages.

\section{Quantitative real time-PCR}

In order to confirm the array findings we used a two step TaqMan quantitative real time-PCR (qRT-PCR) analysis. Synthesis of cDNA from total RNA was performed using the High-Capacity cDNA Archive kit (Applied Biosystems, Foster City, CA, USA) on 0.5-1 $\mu \mathrm{g}$ of RNA from each sample. The reaction was carried out in a GeneAmp PCR System 9700 thermal cycler (Applied Biosystems), under the conditions of an initial hold phase of $25^{\circ} \mathrm{C}$ for $10 \mathrm{~min}$, followed by $2 \mathrm{~h}$ at $37^{\circ} \mathrm{C}$.

A 96-well plate was prepared for the TaqMan Gene Expression Assays (Applied Biosystems). Every well contained $12.5 \mu \mathrm{l}$ of TaqMan Universal master mix, $1.25 \mu \mathrm{l}$ of primer plus probe mix (Assays on Demand from Applied Biosystems), $6.25 \mu \mathrm{l}$ of RNAse-free water and $5 \mu \mathrm{l}$ of cDNA or previously prepared dilutions (reference curve). Dilutions were prepared for 1:10, $1: 100,1: 1000$ and 1:10 000. Every sample and control well was analysed in triplicates and the reference genes in duplicates according to manufacturer's recommendations. A non-template control well was used as negative control in every run. Wells were sealed with MicroAmp Optical caps. Plates were loaded into the ABI PRISM 7700 sequence detection system (Applied Biosystems). In order to select a reference gene for the quantification we used the TaqMan Human Endogenous Control Plate. This evaluates the expression of 11 selected reference genes, using qRT-PCR. The plate also features an internal positive control designed to detect the presence of PCR inhibitors in test samples. The explored genes were: $18 \mathrm{~S}$ rRNA, acidic ribosomal protein, beta-actin, cyclophilin, GAPDH, phosphoglycerokinase, b2-microglobulin, beta-glucoronidase, hypoxanthine ribosyl transferase, transcription factor

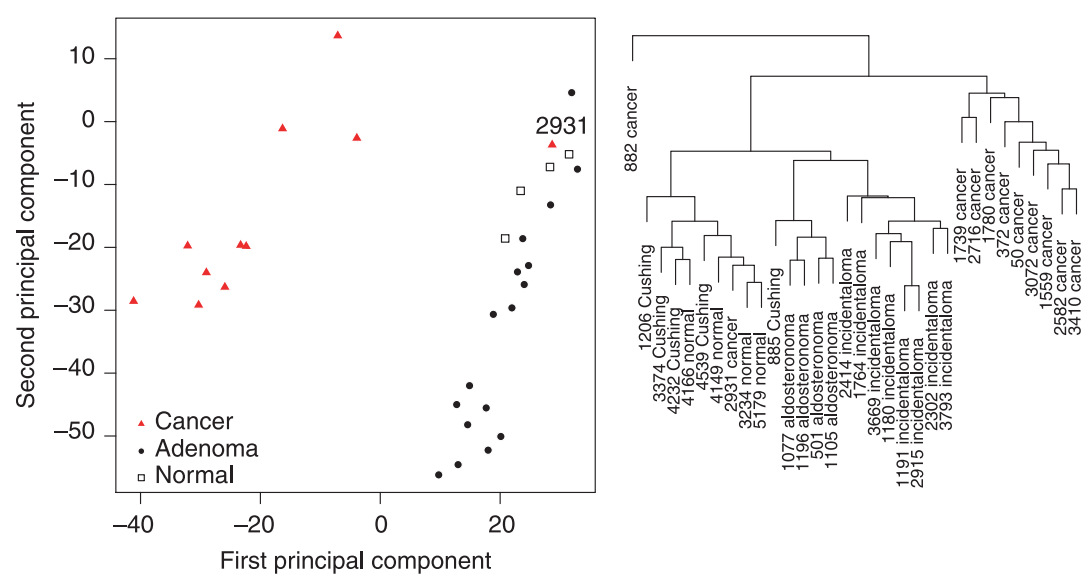

Figure 1 Unsupervised clustering of gene expression profiles in the entire sample set based on all microarray features. Principal component analysis reveals sample similarities and shows that the gene expression is tumour type specific (left). The same observation can be made with hierarchical clustering using Euclidean distances and average linkage (right). 
IID TATA binding protein and the transferrin receptor. The $18 S$ rRNA gene was found to have the most stable expression levels among all samples and was thereby chosen as the reference gene to relate the transcript levels of the target genes. The genes analysed with qRT-PCR were: aldehyde dehydrogenase 1 family member A1 (ALDH1A1), insulin-like growth factor II precursor (IGF2), ubiquitin specific peptidase 4 (USP4) and ubiquitin fusion degradation protein 1 (UFD1L).

\section{Western blot analysis}

Frozen tissues were grounded into powder by mortaring on dry ice and subsequently dissolved by sonication in a buffer containing $50 \mathrm{mM}$ Tris (pH 7.4), $5 \mathrm{mM} \mathrm{MgCl}_{2}$, $250 \mathrm{mM}$ sucrose, $1 \mathrm{mM}$ DTT and $1 \mathrm{mM}$ ATP. The protein extracts were clarified by centrifugation and the lysates were snap-frozen in liquid nitrogen and kept frozen until use. For western blot analysis $20 \mu \mathrm{g}$ protein/sample was fractionated on SDS-PAGE 4-12\% gradient gels (Invitrogen), blotted on PVDF membranes, blocked in PBS supplemented with 5\% skim milk and $0.1 \%$ Tween and probed with anti-Usp4 (C-term) antibody (Abgent Inc., San Diego, CA, USA), diluted 1:500. After subsequent washings and incubation with HRP-conjugated goat anti-rabbit serum (Amersham Biosciences), the blots were developed by ECL (GE Healthcare, Uppsala, Sweden). As a positive control for the Usp4 antibody we transfected human embryonic kidney $293 \mathrm{~T}$ cells with a plasmid expressing USP4 in fusion with green fluorescent protein and harvested the cells for western blot analysis two days post-transfection.

\section{Results}

\section{Classification with unsupervised methods}

Principal component analysis, hierarchical clustering, $k$-means clustering and self-organising maps were applied to the filtered set of 6063 probes with expression values obtained in every tissue sample analysed. The carcinomas and the non-cancers clustered in separate groups with the exception of carcinoma 2931 (Fig. 1). The discrepancy in gene expression is striking and the malignant behaviour seems to be congruent and outrule other inter-individual differences. Interestingly, the adenoma cluster fell into subgroups, with all incidentalomas represented in one group, all aldosteronomas in a second group and normal cortex and Cushing adenomas mixed into a third.

\section{Differential gene expression in cancers}

A $t$-test moderated with an empirical Bayesian statistics was applied to test for differential expression. When carcinomas, except case 2931, were compared to all other samples using the criteria for statistical significance described in Materials and methods, a significantly differential expression was observed for around 300 transcripts, Supplementary file 1A, which can be viewed online at http://www.eje-online.org/supplemental/. The 50 most significantly overexpressed and the 50 most significantly underexpressed transcripts are displayed in Fig. 2. In Supplementary file 1B statistical data for all genes present in all samples is displayed. IGF2, a well established gene overexpressed in
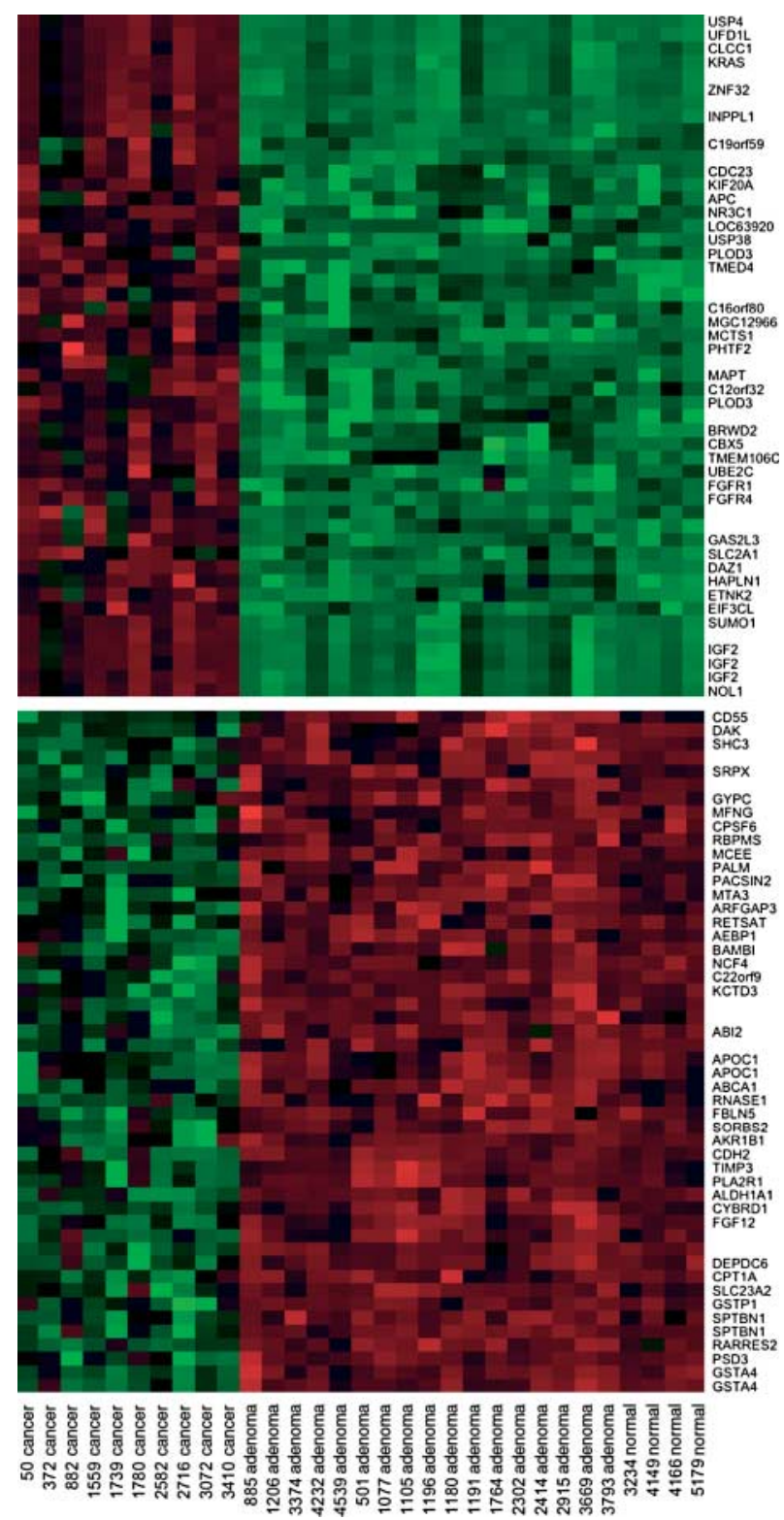

Figure 2 Expression profiles of the 50 most significantly up-regulated (top) and down-regulated (bottom) genes are displayed comparing cancer patients to non-cancer patients. The colour scale ranges from red to green analogous to over- to underexpression. In Supplementary files $1 \mathrm{~A}$ and B, fold changes and $P$ values are given. 
Table 2 Genes with significant differential expression in carcinomas versus non-malignant samples in the Gene Ontology categories of adhesion, mitosis and extracellular location.

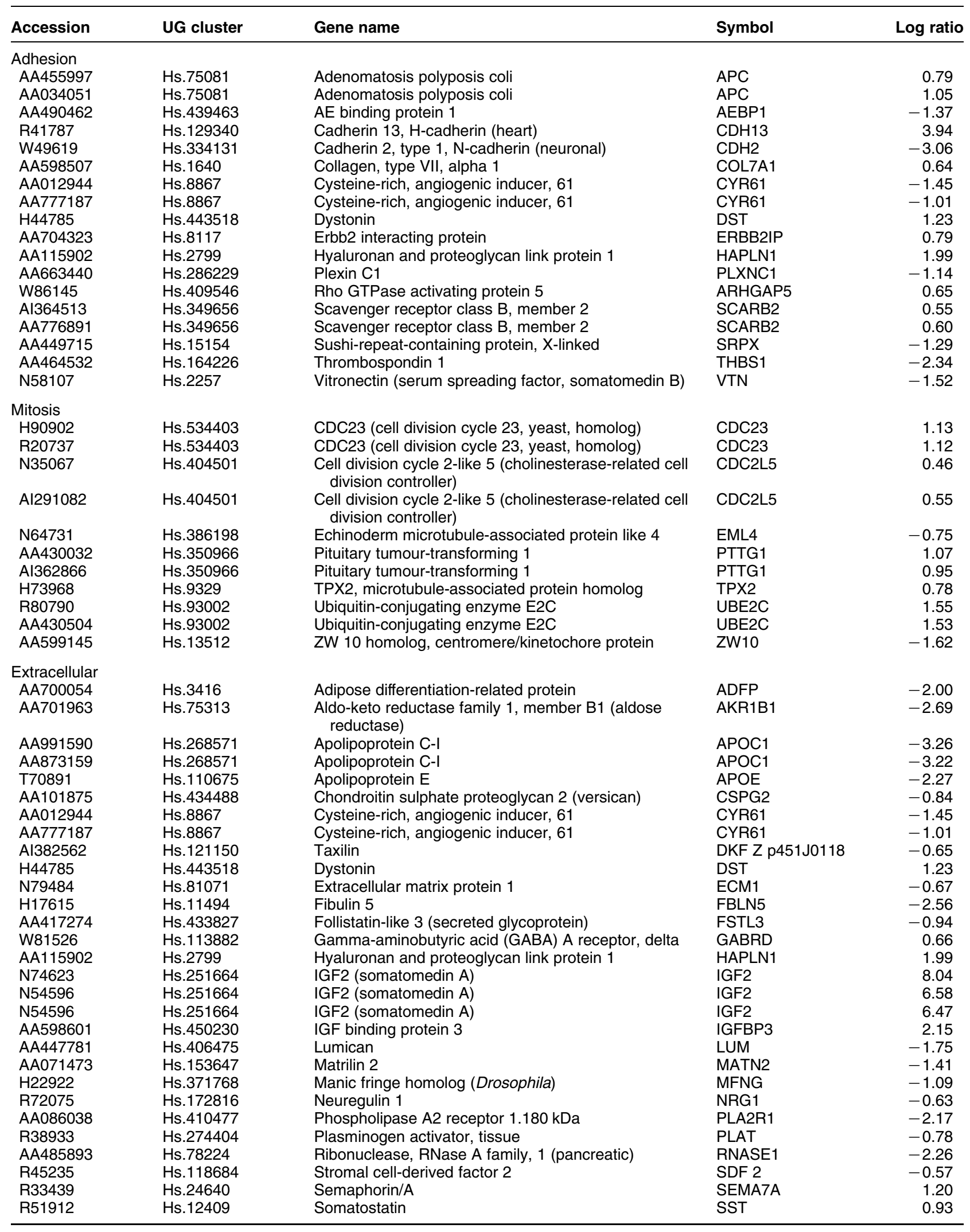


Table 2 Continued

\begin{tabular}{|c|c|c|c|c|}
\hline Accession & UG cluster & Gene name & Symbol & Log ratio \\
\hline AA085319 & Hs.25590 & Stanniocalcin 1 & STC1 & 0.66 \\
\hline AA464532 & Hs. 164226 & Thrombospondin 1 & THBS1 & -2.34 \\
\hline AA479202 & Hs.245188 & Tissue inhibitor of metalloproteinase 3 & TIMP3 & -2.12 \\
\hline N58107 & Hs.2257 & Vitronectin (serum spreading factor, somatomedin B) & VTN & -1.52 \\
\hline
\end{tabular}

adrenocortical cancer, was the most up-regulated transcript. FGFR1 and FGFR4 were up-regulated growth factor receptors.

\section{Enrichment analysis and GO classification of differentially expressed genes in cancers}

An enrichment analysis of the chromosomal location of differentially expressed genes revealed that overexpression on chromosome 5 and underexpression on chromosome 2 and 1 were significant. To investigate which biological processes the differentially expressed genes were involved in, GO annotations were used. Enrichment analysis of the highest ranked differentially expressed transcripts according to statistical significance comparing carcinomas to all other samples showed that anti-apoptosis and cell cycle, were overrepresented among genes with altered transcript levels (Supplementary file 1C). A subset of genes with GO annotation adhesion, mitosis or extracellular location is presented in Table 2 since these categories are of interest in the context of cancer development.

\section{Verification by qRT-PCR}

To confirm microarray results, four of the most significantly differentially expressed genes were analysed with qRT-PCR. qRT-PCR was performed for ALDH1A1, IGF2, USP4 and UFD1L. This confirmed IGF 2 as significantly overexpressed and ALDH1A1 as significantly underexpressed in carcinomas (with the exception of sample 2931) compared to all other samples (Fig. 3). The differences were too small and the variation was too high for USP4 and UFD1L to generate a significant difference. On average the up-regulation was 1.3- and 1.4-fold, respectively, in cancer versus non-cancer samples. The corresponding values for IGF2 was 144-fold up-regulation and 12-fold down-regulation of $A L D H 1 A 1$. Ratios were calculated in a similar way for the array data by taking the average of the ratio for those genes in the cancer samples versus the reference RNA and then divide that with the corresponding ratio for the non-cancer samples. The corresponding fold over-expression for USP4 and UFD1L was 44 and 32 respectively. The corresponding values for IGF2 was 388-fold up-regulation and for ALDH1A1 11-fold down-regulation respectively.

\section{USP4 protein expression is increased in adrenocortical carcinomas}

The microarray data described here indicate a significant overexpression of the deubiquitinating enzyme USP4 (also known as UNP for ubiquitous nuclear protein) in adrenocortical carcinomas compared to adenomas. To test if the increased transcription correlates with elevated protein levels we prepared lysates from tumour biopsies and performed western blot analysis using an anti-USP4 antibody (Fig. 4). A clear increase in a couple of close migrating bands corresponding to the expected
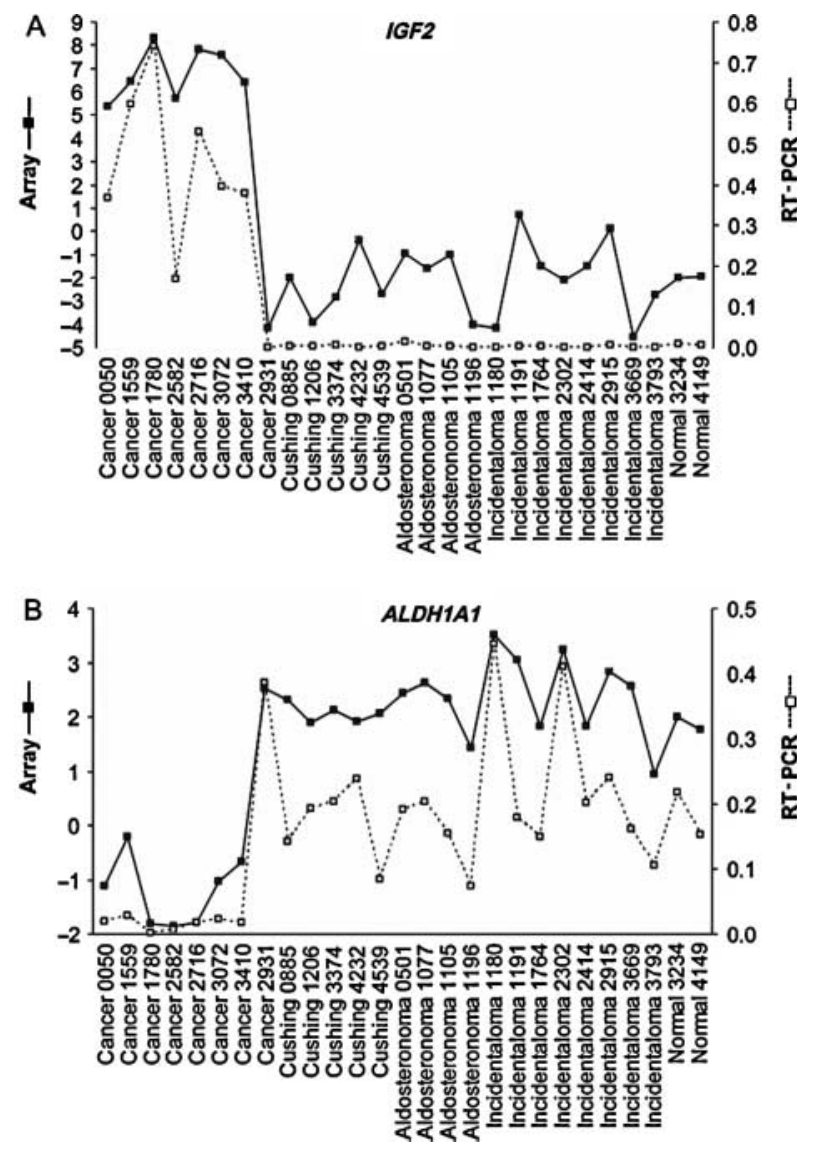

Figure 3 Verification by qRT-PCR. Relative expression levels of (A) IGF2 and (B) ALDH1A1. The array data are displayed as filled squares on the left axes as $\log 2$ ratios versus the common reference RNA and the real time PCR data as open squares on the right axes as ratios in relation to $18 \mathrm{~S}$ rRNA. 


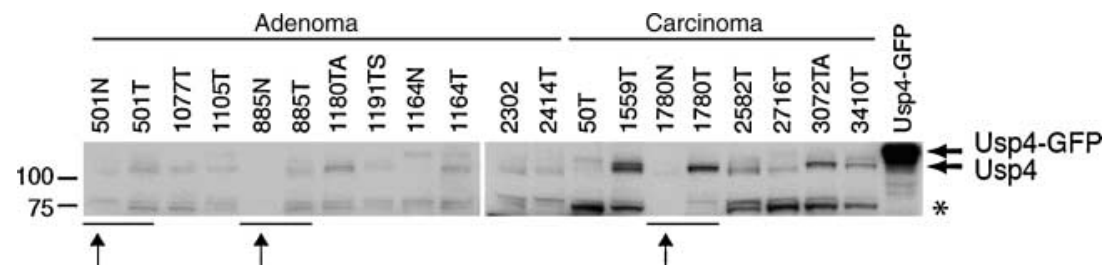

Figure 4 Usp4 protein levels are increased in adrenocortical carcinomas compared with adenomas. Western blot analysis using an anti-USP4 antibody showing increased expression of USP4 protein in adrenocortical carcinomas as compared to adenomas. Underlined are paired samples of tumour $(\mathrm{T})$ and normal adrenal cortex $(\mathrm{N})$ from the same patient. An additional smaller product reacting with the USP4 antibody shows increased expression in carcinomas (asterisk).

size of endogenous USP4 was detected in the carcinoma samples as compared to normal reference. Smaller bands ( $\sim 75 \mathrm{kDa})$ and additional weak bands reacting with the antibody may indicate potential splice variants or cleavage products of USP4.

\section{Survival analysis and gene expression in cancer tumours}

In order to examine if the survival of cancer patients were reflected in the gene expression patterns, cancer data were subject to hierarchical clustering using the entire filtered probe set where each gene profile had been normalised to the same range. The resulting two subclusters had different outcomes; one cluster contained patients with short survival $(<9$ months) and the other patients with long survival $(>67$ months) suggesting that gene expression profiles may be used for prediction of survival. In Fig. 5A, the dendogram based on the entire probe set is displayed together with the gene expression profiles of 30 up- and 30 down-regulated genes. The Kaplan-Meier survival curves of the two subclusters are shown in Fig. 5B.

\section{Differential expression associated with hormonal activity of benign tumours}

The benign tumour sample set consisted of five Cushing, four aldosteronomas and eight non-hormonal overproducing incidentalomas. Comparing each subtype to the other samples we could detect 11 genes with expression levels connected to aldosteronomas using the statistical criteria for differential expression described in Materials and methods (Table 3). In Supplementary file 2A, which can be viewed online at http://www.eje-online.org/supplemental/, data for all probes is shown. Differentially expressed genes were not identified for the other subtypes. Among the dysregulated genes were, vascular endothelial growth factor B (VEGFB) and oxysterol binding protein (OSBP). Comparison of aldosteronomas versus incidentalomas revealed several significantly dysregulated genes as detailed in Supplementary file 2B. Mevalonate kinase $(M V K)$ was up-regulated in aldosteronomas as well as peroxiredoxin 5 (PRDX5), while tumour necrosis factor receptor super family 25 (TNFRSF25) was downregulated (Supplementary files 2B and C).

\section{Discussion}

It is important to elucidate the relation and differences between benign and malignant adrenocortical tumours, both in terms of obtaining an increased understanding for the underlying molecular mechanisms as well as to enhance possibilities for correct diagnosis and prognosis for the individual patient. Previous studies have demonstrated that adrenocortical carcinomas display specific and more numerous chromosomal and/or genetic alterations than adenomas $(4,5)$, which could suggest a characteristic malignant genotype. In a previous study we showed that malignant gene expression profiles are distinguishable from those of benign tumours (16). In this extended study we also included normal adrenal cortex to ascertain that the characteristics that separated cancers from benign tumours were associated with malignancy and not present in normal adrenocortex. We found potentially useful expression profiles which could enable differentiation between carcinomas and non-malignant adrenocortical tissue (normal adrenocortex and adenomas), and furthermore between different subclasses of adenomas. We could also show that in the malignant group tumours from patients with long survival and tumours from patients with short survival fell into two separate cluster groups.

The IGF signalling pathway plays a major role in several cancer forms and is interesting considering development of therapeutics and as a diagnostic approach. IGF2 was up-regulated in adrenocortical carcinomas in this study as in previous published gene expression profiling studies on adrenocortical tumours (21-25). Elevated expression levels of IGF2 has been detected in several other cancer forms (26-28). In a study of ovarian cancer, expression levels of IGF2 have been demonstrated to be inversely correlated to survival (29). Serum levels of IGF2 have been proven to have biomarker potential for tumour staging of prostate cancer as a complement to PSA (30). IGF2 is thus a 

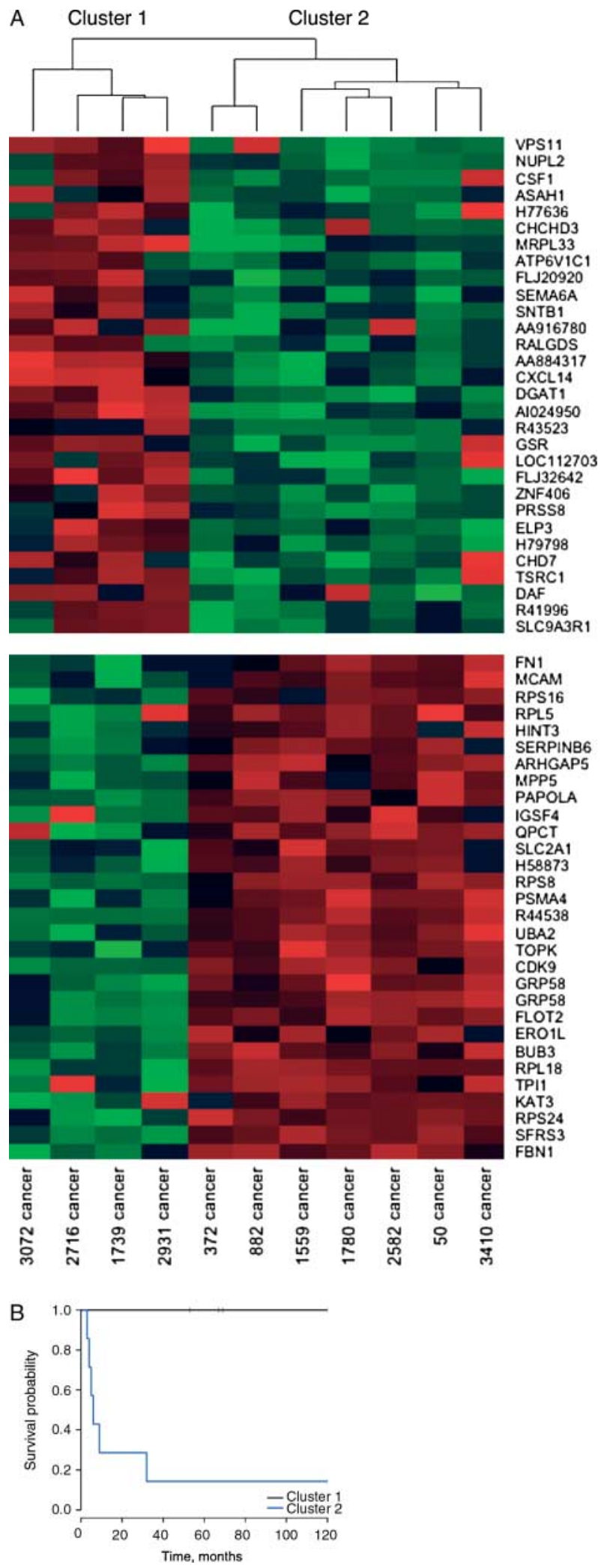

relatively general cancer marker but still has the potential to become very useful to distinguish adrenocortical adenomas from carcinomas.

Several of the up-regulated genes in carcinomas, such as the deubiquitinating enzymes USP4 and USP 38, the ubiquitin conjugating enzyme UBE2C, the small ubiquitin-like modifier SUMO-1 and UFD1L are involved in the ubiquitination pathway (Fig. 2). Posttranslational modification by ubiquitin has emerged as a major regulatory event that is essential for cellular processes such as cell cycle progression, signal transduction, transcriptional regulation, and apoptosis (31). USP4, which was among the most up-regulated genes is an enzyme of yet unclear function, however, its deregulation has previously been linked to cancer and USP 4 has been ascribed oncogenic $(32,33)$ as well as having tumour suppressor functions (34) indicating that it may be a multifunctional protein. USP4 has previously been reported to interact with the retinoblastoma tumour suppressor, $\mathrm{pRb}$, the pocket proteins, p107 and p130 (35, 36), the ubiquitin ligase Ro52 (37) and the transmembrane G-coupled adenosine $2 \mathrm{~A}$ receptor for which it has been suggested to function to relax the endoplasmic reticulum quality control mechanisms, resulting in increased cell surface expression of the receptor (38). The role of USP4 in adrenocortical carcinomas is however, still unexplored. UBE2C (also known as UbcH1O) is a ubiquitin conjugating enzyme involved in cell cycle regulation (39) and its over expression has been suggested to be a valid indicator of human cancers of various tissue origin (40-42).

Differentially expressed genes in carcinomas showed overrepresentation for location on chromosome 5 among genes up-regulated in cancer, while downregulated genes were enriched for chromosome 1 and 2. These observations overlap with those made with CGH showing gains on chromosome 5 and losses on chromosome 2 in adrenocortical cancers (4).

As previously mentioned, we found an interesting cancer case (ID 2931), that surprisingly clustered with normal cortex and adenomas in the unsupervised hierarchical clustering (Fig. 1). This patient had no metastasis at the time of surgery but received mitotane as adjuvant chemotherapy. The patient is still alive 67 months after surgery without any evidence of residual disease or metastasis. The tumour showed low proliferation with MIB-1/Ki- $67,<3 \%$ of activity. Interestingly, this case also showed gene expression levels similar to the 'normal or adenoma' pattern in the qRT-PCR for IGF2 and ALDH1A1 (Fig. 3).

Figure 5 (A) Hierarchical clustering of cancers based on the entire filtered probe set results in two subclusters; cluster 1 and cluster 2. A subset of 30 plus 30 genes with differential expression are displayed beneath. (B) Kaplan-Meier survival curve displays longer survival times for cluster 1 cases as compared to cluster 2 cases. 
Table 3 Differentially expressed genes comparing aldosteronomas to all other tissue samples, (cut off: log fold change $>1$, adjusted $P$ value $<0.001)$.

\begin{tabular}{|c|c|c|c|c|c|c|}
\hline Accession & UniGene & Gene name & Symbol & $\begin{array}{l}\text { Log fold } \\
\text { change }\end{array}$ & Adj. $P$ value & $B$ \\
\hline R99527 & Hs.8162 & Hypothetical protein MGC39372 & MGC39372 & 2.17 & $5.09 \times 10^{-5}$ & 10.16 \\
\hline AA398335 & Hs. 10414 & Hypothetical protein FLJ10748 & FLJ10748 & 2.26 & $5.09 \times 10^{-5}$ & 9.56 \\
\hline AA441933 & Hs.79386 & Leiomodin 1 (smooth muscle) & LMOD1 & 2.33 & $5.09 \times 10^{-5}$ & 9.54 \\
\hline AA630120 & Hs.78781 & $\begin{array}{l}\text { Vascular endothelial growth } \\
\text { factor B }\end{array}$ & VEGFB & 1.24 & $2.93 \times 10^{-4}$ & 7.59 \\
\hline R07846 & Data not found & & & 3.71 & $2.93 \times 10^{-4}$ & 7.49 \\
\hline W92795 & Hs.434386 & Hypothetical protein LOC201229 & LOC201229 & 1.55 & $4.01 \times 10^{-4}$ & 7.03 \\
\hline AA454564 & Hs.323396 & Hypothetical protein RP1-317E23 & LOC56181 & 1.25 & $5.17 \times 10^{-4}$ & 6.65 \\
\hline AA775249 & Hs.6527 & G protein-coupled receptor 56 & GPR56 & -1.63 & $6.42 \times 10^{-4}$ & 6.33 \\
\hline AA012822 & Hs.24734 & Oxysterol binding protein & OSBP & 1.35 & $7.07 \times 10^{-4}$ & 6.14 \\
\hline R45592 & Hs.153610 & $\begin{array}{l}\text { Regulating synaptic membrane } \\
\text { exocytosis } 2\end{array}$ & RIMS2 & 2.51 & $7.11 \times 10^{-4}$ & 6.04 \\
\hline AA282936 & Hs.240 & M-phase phosphoprotein 1 & MPHOSPH1 & -1.40 & $8.87 \times 10^{-4}$ & 5.74 \\
\hline
\end{tabular}

Two recent studies have addressed the connection between gene expression levels and prediction of survival $(23,24)$. Giordano et al. could show that the cancer gene expression signatures divided into two subclusters with different survival outcome suggesting microarrays as a prognostic tool. De Reyniès et al. also found two subclusters with different survival outcomes. In addition, two specific genes (PINK1 and BUB1B) were selected as biomarkers, which in combination could be used for prediction of survival. In our study two subclusters with different survival outcomes could be observed as well. Due to the limited sample set size, we chose not to select any specific markers based on these. However, we could confirm that PINK1 and BUB1B also could be used as predictors for survival in our cases (data not shown) although BUB3 was a better predictor than BUB1B. A weakness of the analysis in our study to take into consideration is that all diseased patients but one (372) are females.

Regarding tumours with different hormonal activity, differences in expression patterns of genes related to steroid hormone synthesis are of special interest. Several interesting genes involved in intermediate metabolism were present on the array, such as the oxysterol binding protein $(O S B P)$ which was found to be up-regulated in aldosteronomas. This gene is involved in sterol transport from lysosomes to the nucleus, down-regulating the expression of other genes such as LDL-receptor, HMG-CoA reductase and HMG synthetase, involved in lipid synthesis. An early enzyme in steroid synthesis is mevalonate kinase $(M V K)$, which was up-regulated in aldosteronomas compared to incidentalomas. Besides genes directly involved in hormonal metabolism, many other genes were found to be differentially expressed in aldosteronomas, among these $V E G F B$, adenosine deaminase (ADA), inositol 1,3,4-triphosphate 5/6 kinase (ITPK1), ubiquitin thiolesterase 1 (UCHL1), tumour necrosis factor receptor super family member 25 (TNFRSF25), and the V-abl Abelson murine leukaemia viral oncogene homolog 1 (ABL1; Supplementary file 2A and B).

\section{Conclusions}

Through the transcriptional profiling, different subtypes of functional adenomas and carcinomas may be distinguished based on their specific molecular signature. This study confirms and extends the findings of previous studies in this respect. Our utilisation of a whole genome cDNA microarray may serve as a complement to gene expression data retrieved with Affymetrix high density microarrays and cDNA macroarrays. Further investigation of the relevance of genes with subtype specific differential expression has the potential to eventually lead to clinical breakthroughs together with the findings of the larger studies recently published. Genes with expression levels connected to malignancy, survival and hormonal activity were detected in our data. Identification of these differentially expressed genes may enhance our understanding of the molecular biology of adrenocortical tumour development and its functional phenotype, and aid in creating new diagnostic and prognostic tools.

\section{Declaration of interest}

We declare that there is no conflict of interest that could be perceived as prejudicing the impartiality of the research reported. C Larsson holds a patent share for VEGFB.

\section{Funding}

This work was supported by the Cancer Society in Stockholm, Gustav V Jubilee Foundation, Swedish Research Council, Swedish Cancer Foundation, Stockholm, County Council and the Consejo Nacional de Ciencia y Tecnología (CONACYT, México) and Göran Gustafsson foundation for research in natural sciences and medicine.

\section{Acknowledgements}

We thank Elisabet Ånfalk, Jia Jing Lee, Andrea Villablanca and Roberto Vázquez-Dávila for the technical expertise and assistance and Annelie Waldén for the microarray production. 


\section{References}

1 Hedeland H, Ostberg G \& Hokfelt B. On the prevalence of adrenocortical adenomas in an autopsy material in relation to hypertension and diabetes. Acta Medica Scandinavica $1968 \mathbf{1 8 4}$ 211-214.

2 Boushey RP \& Dackiw AP. Adrenal cortical carcinoma. Current Treatment Options in Oncology 20012 355-364.

3 Dackiw AP, Lee JE, Gagel RF \& Evans DB. Adrenal cortical carcinoma. World Journal of Surgery 200125 914-926.

4 Kjellman M, Kallioniemi OP, Karhu R, Hoog A, Farnebo LO, Auer G, Larsson C \& Backdahl M. Genetic aberrations in adrenocortical tumors detected using comparative genomic hybridization correlate with tumor size and malignancy. Cancer Research 199656 4219-4223.

5 Kjellman M, Roshani L, Teh BT, Kallioniemi OP, Hoog A, Gray S, Farnebo LO, Holst M, Backdahl M \& Larsson C. Genotyping of adrenocortical tumors: very frequent deletions of the MEN1 locus in 11q13 and of a 1-centimorgan region in 2p16. Journal of Clinical Endocrinology and Metabolism 199984 730-735.

6 Sidhu S, Gicquel C, Bambach CP, Campbell P, Magarey C, Robinson BG \& Delbridge LW. Clinical and molecular aspects of adrenocortical tumourigenesis. ANZ Journal of Surgery $2003 \mathbf{7 3}$ 727-738.

7 Volante M, Buttigliero C, Greco E, Berruti A \& Papotti M. Pathological and molecular features of adrenocortical carcinoma: an update. Journal of Clinical Pathology 200861 787-793.

8 Kendrick ML, Lloyd R, Erickson L, Farley DR, Grant CS, Thompson GB, Rowland C, Young WF Jr \& van Heerden JA. Adrenocortical carcinoma: surgical progress or status quo? Archives of Surgery 2001136 543-549.

9 Herbet M, Feige JJ \& Thomas M. Insights into the role of genetic alterations in adrenocortical tumorigenesis. Molecular and Cellular Endocrinology 2009300 169-174.

10 Koch CA, Pacak K \& Chrousos GP. The molecular pathogenesis of hereditary and sporadic adrenocortical and adrenomedullary tumors. Journal of Clinical Endocrinology and Metabolism 200287 5367-5384.

11 Libe R \& Bertherat J. Molecular genetics of adrenocortical tumours, from familial to sporadic diseases. European Journal of Endocrinology 2005153 477-487.

12 Golub TR, Slonim DK, Tamayo P, Huard C, Gaasenbeek M, Mesirov JP, Coller HL, Loh M, Downing JR, Caligiuri MA, Bloomfield CD \& Lander ES. Molecular classification of cancer: class discovery and class prediction by gene expression. Science $1999286531-537$.

13 Perou CM, Sørlie T, Eisen MB, van de Rijn M, Jeffrey SS, Rees CA, Pollack JR, Ross DT, Johnsen H, Akslen LA, Fluge O, Pergamenschikov A, Williams C, Zhu SX, Lønning PE, BørresenDale AL, Brown PO \& Botstein D. Molecular portraits of human breast tumours. Nature $2000 \mathbf{4 0 6}$ 747-752.

14 Sørlie T, Tibshirani R, Parker J, Hastie T, Marron JS, Nobel A, Deng S, Johnsen H, Pesich R, Geisler S, Demeter J, Perou CM, Lønning PE, Brown PO, Borresen-Dale AL \& Botstein D. Repeated observation of breast tumor subtypes in independent gene expression data sets. PNAS $20031008418-8423$.

15 Hedenfalk I, Duggan D, Chen Y, Radmacher M, Bittner M, Simon R, Meltzer P, Gusterson B, Esteller M, Kallioniemi OP, Wilfond B, Borg A, Trent J, Raffeld M, Yakhini Z, Ben-Dor A, Dougherty ER, Kononen J, Bubendorf L, Fehrle W, Pittaluga S, Gruvberger S, Loman N, Johannsson O, Olsson H \& Sauter G. Gene-expression profiles in hereditary breast cancer. New England Journal of Medicine 2001 344 539-548.

16 Velazquez-Fernandez D, Laurell C, Geli J, Hoog A, Odeberg J, Kjellman M, Lundeberg J, Hamberger B, Nilsson $\mathrm{P}$ \& Backdahl M. Expression profiling of adrenocortical neoplasms suggests a molecular signature of malignancy. Surgery 2005138 1087-1094.
17 Weiss LM, Medeiros LJ \& Vickery AL Jr. Pathological features of prognostic significans in adrenocortical carcinoma. American Journal of Surgical Pathology 198913 202-206.

18 R-Development-Core-Team. R: A Language and Environment for Statistical Computing Vienna, Austria 2005.

19 Bengtsson H. Aroma - An R Object-Oriented Microarray Analysis Environment, Mathematical Statistics, Lund University 2005.

20 Smyth GK. Linear models and empirical bayes methods for assessing differential expression in microarray experiments. Statistical Applications in Genetics and Molecular Biology 20043. Article 3.

21 Slater E, Diehl S, Langer P, Samans B, Ramaswamy A, Zielke A \& Bartsch D. Analysis by cDNA microarrays of gene expression patterns of human adrenocortical tumors. European Journal of Endocrinology $2006 \mathbf{1 5 4} 587-598$.

22 de Fraipont F, El Atifi M, Cherradi N, Le Moigne G, Defaye G, Houlgatte R, Bertherat J, Bertagna X, Plouin P, Baudin E, Berger F, Gicguel C, Chabre O \& Feige JJ. Gene expression profiling of human adrenocortical tumors using complementary deoxyribonucleic acid microarrays identifies several candidate genes as markers of malignancy. Journal of Clinical Endocrinology and Metabolism 2005 90 1819-1829.

23 Giordano TJ, Thomas DG, Kuick R, Lizyness M, Misek DE, Smith AL, Sanders D, Aljundi RT, Gauger PG, Thompson NW, Taylor JM \& Hanash SM. Distinct transcriptional profiles of adrenocortical tumors uncovered by DNA microarray analysis. American Journal of Pathology 2003162 521-531.

24 Giordano T, Kuick R, Else P, Gauger P, Vinco M, Bauersfeld J, Sanders D, Thomas D, Doherty G \& Hammer G. Molecular classification and prognostication of adrenocortical tumors by transcriptome profiling. Clinical Cancer Research $2009 \mathbf{1 5}$ 668-676.

25 de Reyniès A, Assié G, David S, Tissier F, Groussin F, Dousset B, Bertagna X, Claueser E \& Bertherat J. Gene expression profilling reveals a new classification of adrenocortical tumors and identifies molecular predictors of malignancy and survival. Journal of Clinical Oncology 200927 1108-1115.

26 Nosho K, Yamamoto H, Takamaru H, Hamamoto Y, Goto A, Yoshida Y, Arimura Y, Endo T, Hirata K \& Imai K. A case of colorectal carcinoma in adenoma analyzed by a cDNA array. International Journal of Colorectal Disease 200520 287-291.

27 Wrobel G, Roerig P, Kokocinski F, Neben K, Hahn M, Reifenberger G \& Lichter P. Microarray-based gene expression profiling of benign, atypical and anaplastic meningiomas identifies novel genes associated with meningioma progression. International Journal of Cancer $2005114249-256$.

28 Li H \& Zhang N. Study on the expression and genomic imprinting status of insulin-like growth factor 2 gene in hepatocellular carcinoma. Zhonghua Gan Zang Bing Za Zhi 200412 347-349.

29 Sayer R, Lancaster J, Pittman J, Gray J, Whitaker R, Marks J \& Berchuck A. High insulin-like growth factor-2 (IGF-2) gene expression is an independent predictor of poor survival for patients with advanced stage serous epithelial ovarian cancer. Gynecologic Oncology 200596 355-361.

30 Trojan L, Bode C, Weiss C, Mayer D, Grobholz R, Alken P \& Michel M. IGF-II serum levels increase discrimination between benign prostatic hyperplasia and prostate cancer and improve the predictive value of PSA in clinical staging. European Urology 2006 49 286-292.

31 Glickman MH \& Ciechanover A. The ubiquitin-proteasome proteolytic pathway: destruction for the sake of construction. Physiological Reviews 200282 373-428.

32 Gray DA, Inazawa J, Gupta K, Wong A, Ueda R \& Takahashi T. Elevated expression of Unph, a proto-oncogene at 3p21.3, in human lung tumors. Oncogene 199510 2179-2183.

33 Gupta K, Chevrette M \& Gray DA. The Unp proto-oncogene encodes a nuclear protein. Oncogene 19949 1729-1731.

34 Frederick A, Rolfe M \& Chiu MI. The human UNP locus at 3p21.31 encodes two tissue-selective, cytoplasmic isoforms with deubiquitinating activity that have reduced expression in small cell lung carcinoma cell lines. Oncogene 199816 153-165. 
35 Blanchette P, Gilchrist CA, Baker RT \& Gray DA. Association of UNP, a ubiquitin-specific protease, with the pocket proteins $\mathrm{pRb}$, p107 and p130. Oncogene 200120 5533-5537.

36 DeSalle LM, Latres E, Lin D, Graner E, Montagnoli A, Baker RT, Pagano M \& Loda M. The de-ubiquitinating enzyme Unp interacts with the retinoblastoma protein. Oncogene 200120 5538-5542.

37 Di Donato F, Chan EK, Askanase AD, Miranda-Carus M \& Buyon JP. Interaction between $52 \mathrm{kDa}$ SSA/Ro and deubiquitinating enzyme UnpEL: a clue to function. International Journal of Biochemistry and Cellular Biology 200133 924-934.

38 Milojevic T, Reiterer V, Stefan E, Korkhov VM, Dorostkar MM, Ducza E, Ogris E, Boehm S, Freissmuth M \& Nanoff C. The ubiquitin-specific protease Usp4 regulates the cell surface level of the A2A receptor. Molecular Pharmacology 200669 1083-1094.

39 Rape M \& Kirschner MW. Autonomous regulation of the anaphase-promoting complex couples mitosis to S-phase entry. Nature 2004432 588-595.
40 Berlingieri MT, Pallante P, Guida M, Nappi C, Masciullo V, Scambia G, Ferraro A, Leone V, Sboner A, Barbareschi M, Ferro A, Troncone G \& Fusco A. UbcH10 expression may be a useful tool in the prognosis of ovarian carcinomas. Oncogene 2007 $262136-2140$.

41 Ieta K, Ojima E, Tanaka F, Nakamura Y, Haraguchi N, Mimori K, Inoue $\mathrm{H}$, Kuwano $\mathrm{H} \&$ Mori M. Identification of overexpressed genes in hepatocellular carcinoma, with special reference to ubiquitin-conjugating enzyme E2C gene expression. International Journal of Cancer 2007121 33-38.

42 Okamoto Y, Ozaki T, Miyazaki K, Aoyama M, Miyazaki M \& Nakagawara A. UbcH10 is the cancer-related E2 ubiquitinconjugating enzyme. Cancer Research 200363 4167-4173.

Received 9 April 2009

Accepted 18 April 2009 